\title{
VSWR value measurement analysis using Direct Digital Synthesizer
}

\author{
Lorenza Louis Natalia ${ }^{1}$, Slamet Widodo.., Budi Basuki Subagio ${ }^{3}$ \\ ${ }_{1,2,3}$ Electrical Engineering Department, Polytechnic State Semarang, Semarang, Indonesia \\ lorenza.tenggara@gmail.com ${ }^{1}$, maswied105@gmail.com ${ }^{2}$, budi.basuki2010@gmail.com $^{3}$
}

\begin{abstract}
SWR Analyzer is an electronic device radio is useful to know the value of VSWR and antenna impedance without the use of radio tranciever. In this final use Direct Digital Synthesizer (DDS) to generatewaveforms analog digitally. DDS signal generation programmable via Arduino nano. The frequency used is aantenna operating frequency dipole $7 \mathrm{MHz}$ which are in the range $6.9 \mathrm{MHz}$ -

7.4 MHz.calibration SWR Analyzer is done by providing a form of pure resistor load with the acquisition of a data error of $4 \%$ as compared with the theory. The test results niali VSWR atantenna dipole 7 MHzusing an SWR Analyzer then compared with measuring devices in general, ie VSWR SWR meter. Earned value matching 1: 1 obtained by SWR Analyzer at a frequency of $6.9 \mathrm{MHz}$, while using the SWR meter lowest VSWR values obtained at 7:04 MHz frequency with a value ofratio matching impedance1:35: 1. The accuracy of the measurement results using the SWR Analyzer when compared with SWR meter reaches a value $83 \%$.
\end{abstract}

Index Terms—AD9850 DDS; SWR Analyzer; Dipole antenna; VSWR

\section{INTRODUCTION}

DDS is a technique ofgeneratingwaveforms analog digitally that are very accurate in frequency synthesizing, by means of digital signal generation and then converted intoform analog using a digital to analog converter where the frequency is raised can be changed as needed [1]. DDS works on the principle that digitized. Given frequency waveforms can be generated by collecting a phase change at a higher frequency.

In our study DDS wave generator is used as the $S W R A n a l y z e r . I n$ general SWR Analyzer is a radio electronic devices capable of providing the interpretation of the value of the impedance and SWR. Methods and techniques to build SWR Analyzer is very diverse. The simplest technique is to compare the voltage of forward and backward so it can only display the SWR while for the more complex techniques SWR Analyzer is also capable of displaying the frequency, antenna input resistance $(\mathrm{R})$, the resistance of the output antenna $(\mathrm{X})$ which is

equipped with a polarization. SWR Analyzer can be used as penggan SWR meter without using tranciever when measuring VSWR. In the era of microcontroller, $S W R$

Analyzer is built with an Arduino so that it can perform mathematical operations

and frequency calculations are then displayed on a PC or laptop.
SWR Analyzer utilizing Arduino programming to generate sine signal and applied to the measurement of the HF band dipole antenna with $7 \mathrm{MHz}$ operating frequency.

In this final project designed a SWR Analyzer simplespecifications and outcomes are not much different from the SWR Analyzer existing at a lower cost. AD9850 DDS is able to generate a signal frequency of $1 \mathrm{~Hz}-40 \mathrm{MHz}$, the frequency range can be used for testing the HF antenna.

Research conducted on the SWR Analyzer has three treatments, namely: experimental measurement of antenna analyzer with a pure resistor, experimental measurement with dummy load antenna analyzer and antenna analyzer measurement experiments on the $\mathrm{HF}$ antenna $7 \mathrm{MHz}$.

\section{II.SWR ANALYZER}

SWR Analyzer is a radio electronic devices capable of providing the interpretation of the value of the impedance and SWR [2]. Methods and techniques to build SWR Analyzer is very diverse. The simplest technique is to compare the voltage of forward and backward so it can only display the SWR while for the more complex techniques SWR Analyzer is also capable of displaying the frequency, antenna input resistance $(\mathrm{R})$, the resistance of the output antenna $(\mathrm{X})$ which is equipped with a polarization. Antenna analyzer can be used as a substitute for an SWR meter. In the era of microcontroller, SWR Analyzer is built with an Arduino so that it can perform mathematical operations and frequency calculations are then displayed on a PC or laptop. 
SWR Analyzer created has five important parts are: DDS, microcontroller, VSWR bridge, Thrifty Antenna Software Sweeper, and Antenna.

\subsection{DIRECT DIGITAL synthesizer}

DDS is a technique of digitally generating analog waveforms that are very accurate in frequency synthesizing, by means of digital signal generation and then converted into analog form using a digital to analog converter where the frequency is raised can be changed according to the needs users [1].

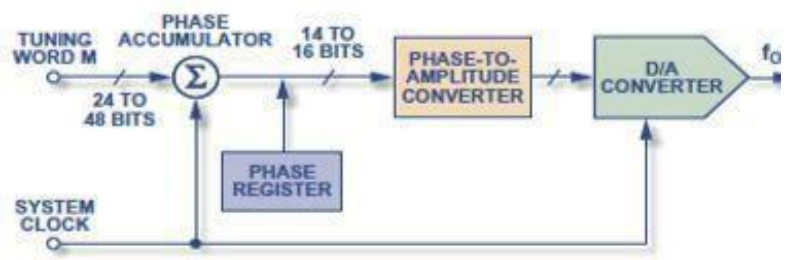

Fig. 1 Diagram Blog DDS [1]

Phasse accumulator is one part of the DDS system which has the duty to change the input of the tuning word in the form of the phase angle. Sine signal has a phase angle ranging from 0 to $360^{\circ}$. Phase accumulator also called modulo-M counter which raise numbers stored each receive a clock pulse with a rise in the amount specified by the binary code in theinput word $(\mathrm{M})$. Input word $(M)$ is a bigdetermines the step phase at each reference clock update, to determine how many points that is passed around the circle phase. The larger the jump performed on the phase circle, the faster the phase accumulator generates a sine wave cycle. Numbers are available in each point depends on the resolution of the phase accumulator ( $n$ )which is the tuning resolution of the DDS. For $n=32$-bit phaseaccumulator, the value of $M$ from 0000 ... 0001 will meet the phase

accumulator after $2^{32}$ cycles. reference clockCalculations to determine thefrequency of output the DDS can be done using the formula [3]:

$$
\begin{aligned}
& f_{\text {out }}=\frac{M x f c M x f c}{2^{n} 2^{n}} \\
& \text { Where: } \\
& f_{\text {out }}=\text { frequency output DDS } \\
& \mathrm{M} \quad=\text { value tunning word } \\
& f_{c} \quad=\text { refrence clock } \\
& \mathrm{n} \quad=\text { length of the phase accumulator }
\end{aligned}
$$

\section{A. Part - Part DDS}

DDS has two general parts schematically namely digital and analog.

1. Digital section called the Numerically Controlled Oscillator (NCO) who runs the digital computing when givenfrequency, clockthe digital part consists of a phase accumulator, phase truncated and look sinetable.

2. Analog part consists of a Digital to Analog

Converter and filter, in this section has been given asignal which clock is then converted into an analog signal.

DDS has a groove performance is divided into three parts:

1. DDS itself as a signal generator which has a basic oscillator circuit therein

2. LPF (Low Pass Filter) is used to convert the DDS output in the form of non-continuous signal into a continuous signal, $L P F$ also eliminates harmonic signals produced by DDS

3. RF amplifier that is used to adjust the amplitude of the DDS output as a whole.

The chip contained within a DDS or often referred to as the Micro Controller Unit (MCU) consists of 2 pieces of 16F628A, the fruit is used to mendrive IC in order to be able to function as a DDS, while the fruit is again used for switching additional parts in accordance with bands included in DDS [4].

\section{B. How it WorksDDS}

Phase accumulator and DAC is a major component in the DDS, this section will generate a sine signal at a specific frequency based on reference clock and the binary number in the form of tuning word. Tuning word determines the main input to the phase accumulator.

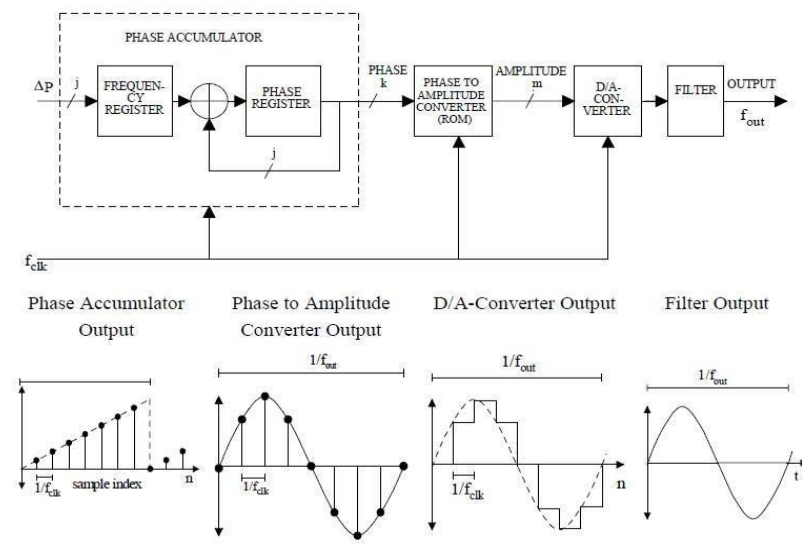

Fig. 2 The process of formation of the DDS sine signal [3]

Phase accumulator will calculate the phase angle based on sine table, where output is converted by the phase-to-amplitude converter into a digital amplitude corresponding to the phase angle which would then be sent to the DAC. In the DAC, input thewill be converted into the appropriate voltage value. To generate a sine wave which is fixed, constant value (phase increment specified by binary numbers) will be added to the phase accumulator at every clock cycle. If the rise in major phase, the phase accumulator will step slightly (jump quickly) and will produce high-frequency sine wave. If the phase increment is small, the phase accumulator will step more, resulting in a low-frequency sine wave. 


\subsection{MIKROKONTROLER}

Micro is small while the controller is the controller. Microcontroller is a control device in the form of a single chip that has input and output as well as the control program can be written and erased repeatedly. However microcontroller only has one or several different specific tasks with a PC that has a variety of functions. In addition to small size, the tool is able to suppress the effectiveness and efficiency of the manufacturing cost so that it becomes more economical to size a control device. The microcontroller typically used in automatically controlled tools such as engine control systems, remotecontrol,home appliances, robotics, and others others.

The microcontroller typically consists of: $\mathrm{CPU}$ (Central ProcessingUnit),RAM and ROM, I / O, timers, and interrupt [5].

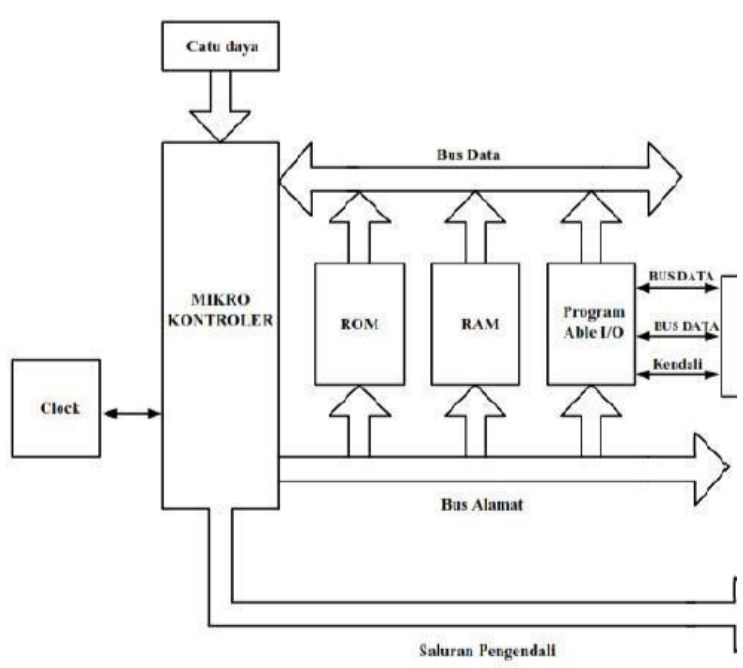

Fig. 3 Block Diagram of Microcontroller general

\section{[5] 2.3 BRIDGE VSWR}

VSWR Bridge is an electronic circuit made on a single PCB layer that consists of two main blocks, namely a diode detector and DC Voltage Amplifier.

\section{A. Diode detector}

In this Section diode detector function, namely as a voltage divider, using the main component diodes Germanium types 1N34A that have been commonly used as a series of detector associated with the radio, the diode is a type of diode rectifier that can work until the $H F$ band and has a forward current which is quite small, so it has a higher accuracy than using a silicon diode.

In this system the diode used is a diode-type germanium with 1N34A. Germanium diodes used in radio detector circuit or circuit that produces output a largepower.These diodes withstand high voltages up to 500 volts and a current of up to 10 ampare with the possibility of missing voltage 0.7 volt.

\section{B. DC Voltage Amplifier}

At block diode detector has a weakness where the diode has a non-linear nature of early-early when ON it can lead to inaccuracy of data and therefore required a series of voltage amplifier with gain adjustment to compensate ketidalinearannya order to obtain accurate data. Besides this circuit also serves to strengthen the DC voltage going into the Arduino.

This block is formed by utilizing an IC OP-AMP isMCP6002. MCP6002 ICis a series Op-Amp that has been packaged into an IC that is much cheaper and widely used. This IC has two op-amp main functions to perform mathematical linear operating voltage and current, and gains then developed as a circuit that amplify DC or AC input signal.

\subsection{Thrifty ANTENNA SWEEPER}

toapplications sweep test there are several versions of this thesis using Antenna Thrifty Sweeper application because this version is an open sourceversion.

This app serves to show the value of the lowest VSWR at the desired frequency range in the form of point coordinates. This application has a connection withArduino which the port Arduinois connected to the laptop using the USB cable mini B.

The application includes all the bands on HF signal that comes with the option to select a frequency band antenna to be measured and automatically displays the range and frequency step.button Sweep on the app function to display graphs antenna VSWR a test, so it can be low VSWR value of the antenna.

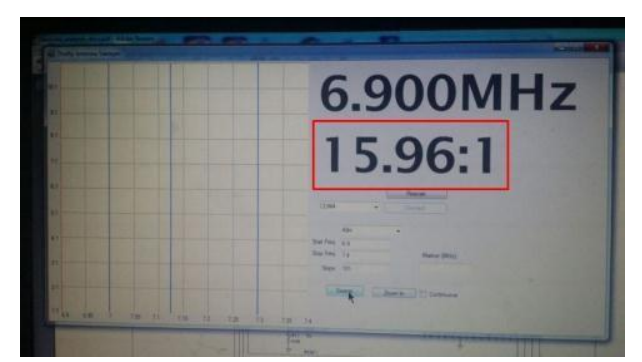

Fig. 4 Display Software Sweeper Thrifty Antenna

\subsection{Antenna}

antenna definition according to Webster'sDictionary,is a device made of metal that can transmit and receive radio waves, while according to the IEEE StandardDefinition, the antenna is a device that can transmit and receive waves [6].

The antenna is an important element that exist in every system of cordless telecommunications (LAN / Wireless), no telecommunications system does not have an antenna. The antenna as the transmitter (transmitting antenna) is a transducer (converter) electromagnetic, which is used to change the wave guided in the cable channel cable transmission into 
waves that propagate in free space, and as a receiver (receiving antenna) that turn the tide of free space into guided wave [7].
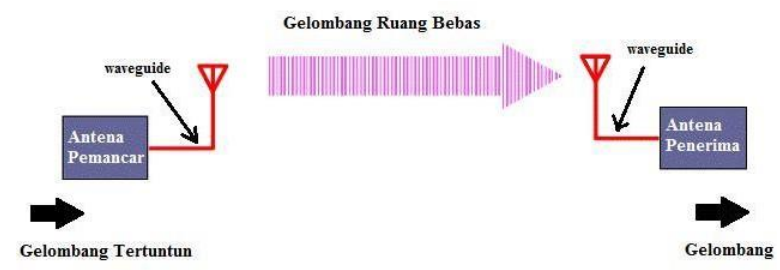

Fig. 5 The role of antennas in wireless communication systems [7]

Each wireless communication system there is a component that could change in the transmission cable guided wave into a wave of free space and its opposite, this component is the antenna. The strength of the antenna to receive or send a signal known as gain / strengthening of the antenna. Unit to measure the gain is $\mathrm{dBi}$ antenna.

In this final task antennas used is a dipole antenna on the HF bands with a frequency of $7 \mathrm{MHz}$. This frequency is the frequency which is generally used by amateurs belonging to ORARI, with a theoretical calculation as follows [2]:

$\lambda=\frac{300}{7} \cdot 0.95$

$\lambda=40.7144$ meter

$1 / 2 \lambda=20.35$ meter

In accordance with the calculation of the length of the dipole antenna to the working frequency of $7 \mathrm{MHz}$ is 20.4 meters.

\section{SYSTEM ILLUSTRATION}

tool is meant to determine the value of the lowest VSWR an antenna, by connecting the HF antenna to be measured on the SWRAnalyzer.Then using test Sweep application was chosen frequency band antenna to be tested. The application displays a graph of antenna VSWR test, the graph can be known frequency with low VSWR. If it has been measured VSWR <2, it can be ascertained that the antenna under test has been matched by transmisiya channel (koasksial). Antenna Analyzer can be used on several HF band antenna.

After getting the results of impedance and VSWR measurements by SWRAnalyzer, the next is to compare the measurement results using the same antenna SWR meter. This is done so that the data obtained valid.Here is an overview of the overall system:

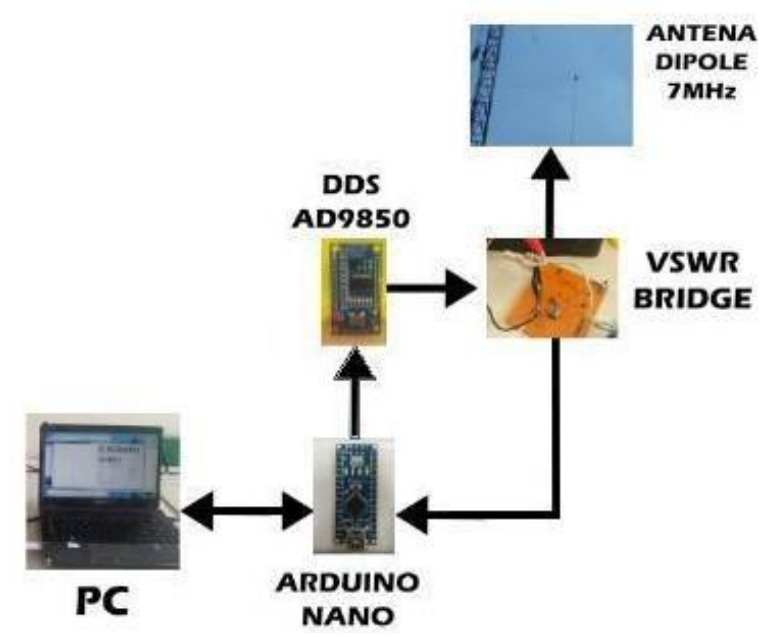

Fig. 6 system topology SWR Analyzer

PC software used to access the sweep test gave input on the arduino, the data coming from the PC and then processed by the arduino so as to produce an output which is forwarded to the AD9850 DDS and processed to produce output sine signal and forwarded to the VSWR bridge. After being processed in VSWR bridge, this section produces two outputs are forwarded to the dipole antenna VSWR value measurement and or repeat the arduino to get a good VSWR.

\section{TESTING AND RESULTS}

Tests were performed divided into two parts, namely the normalization of testing instruments and testing tools to antenadipole $7 \mathrm{MHz}$ to measure VSWR.

\section{TEST RESULTS FREQUENCY OUTPUT AD9850 DDS}

initial step of testing tools that test the accuracy of the output signal generated by the AD9850 DDS. The results of such testing in Table 1.

\begin{tabular}{|c|c|c|c|c|c|}
\hline \multirow{2}{*}{$\begin{array}{c}\text { DDS } \\
\text { Frequency }\end{array}$} & Trial 1 & Trial 2 & Trial 3 & $\begin{array}{c}\text { Average } \\
\text { Freq }\end{array}$ & $\begin{array}{c}\text { Data } \\
\text { Aquracy }\end{array}$ \\
\cline { 2 - 5 } & 7.39991 & 7.399911 & 7.399912 & 7.399911 & 93 \\
\hline 6.9 & 7.399909 & 7.399911 & 7.399910 & 7.39991 & 93 \\
\hline 6.91 & 7.39991 & 7.399911 & 7.399912 & 7.399911 & 95 \\
\hline 7.039 & \multicolumn{4}{|c|}{ Aquracy Average } & $\mathbf{9 3 \%}$ \\
\hline \multicolumn{7}{|c|}{}
\end{tabular}

based on the testing that was done, at a frequency of $6.9 \mathrm{MHz}$ output DDS is best produced in experiment 3 is 7.399912. At 6.91frequency output the bestis generated when the experiment 2 is 7.399911 at a frequency of $7039 \mathrm{MHz}$, whileresults output the bestin experiment 3 is 7.399912. Third frequency data generated can be graphed on average as in Figure 7 


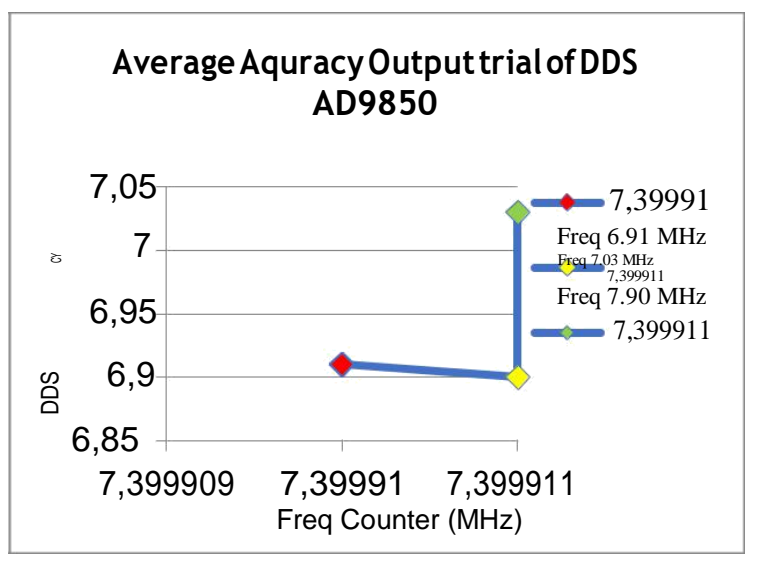

Fig. 7 Graph Accuracy Output DDS AD9850

\section{TEST RESULTS OUTPUT FREQUENCY VSWR BRIDGE}

After testing at the output of DDS further signal back in check keakurasianya at the output VSWR Bridge with the acquisition of the following data in Table 2:

\begin{tabular}{|c|c|c|c|c|c|}
\hline \multirow{2}{*}{$\begin{array}{c}\text { Frekuensi } \\
\text { DDS }\end{array}$} & \multicolumn{4}{|c|}{ Result Frequency Counter } & \multirow{2}{*}{$\begin{array}{r}\text { Data } \\
\text { Aquracy }\end{array}$} \\
\hline & Trial 1 & Trial 2 & Trial 3 & $\begin{array}{c}\text { Average } \\
\text { rrey }\end{array}$ & \\
\hline 7.034 & 7.399873 & 7.193506 & 7.399905 & 7.331095 & $95 \%$ \\
\hline 7.306 & 7.221457 & 7.399905 & 7.399906 & 7.340423 & $99 \%$ \\
\hline 7.341 & 7.39991 & 7.399911 & 7.399912 & 7.399911 & $99 \%$ \\
\hline \multicolumn{5}{|c|}{ Rata-rata Akurasi } & $98 \%$ \\
\hline
\end{tabular}

Testing frequency at the output of the antenna is done using frequency counter for getting data more accurate. The frequency used is $7034 \mathrm{MHz}, 7306$ $\mathrm{MHz}$ and $7341 \mathrm{MHz}$. At each frequency 3 times the experiment so that it can be seen the average accuracy of the data. Data in the table can be made into a graph as in figure 8 .

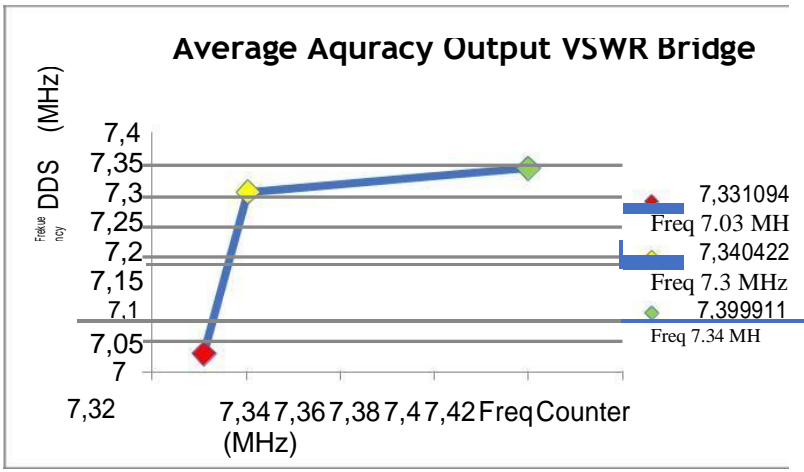

Fig. 8 Graph BridgeAccuracy Output VSWR

MeasurementVSWR value in this research using SWR Analyzer SWR meterand which serves as a comparison. SWR meter is a measure commonly used to measure antenna VSWR. Measurements were performed 3 times the experiment is to use a pure resistor, using a dummy load and measurements on $\mathrm{HF}$ dipole antenna with a frequency of $7 \mathrm{MHz}$.

\section{TEST RESULTS SWR ANALYZER WITH PURE RESISTOR}

Tests using pure resistor intended for calibration measurement accuracy when compared with the theory as follows [8]:

$$
\begin{array}{ll}
\text { VSWR }=\frac{Z_{L}}{Z_{0}} & \rightarrow \text { untuk } Z_{L} \geq Z_{0} \\
V S W R=\frac{Z_{0}}{Z_{L}} & \rightarrow \text { untuk } Z_{0} \geq Z_{L}
\end{array}
$$

Where:

$\mathrm{Z}_{\mathrm{L}}=$ Load Impedance (Antenna)

$Z_{O}=$ The characteristic impedance of the transmission line

experiments on resistor done as much as 7 times using a resistor $75 \Omega, 68 \Omega, 82 \Omega, 100 \Omega, 120 \Omega, 150 \Omega, 200$

$\Omega$, the test results are presented in table 3 .

\begin{tabular}{|c|c|c|c|c|}
\hline $\mathbf{Z 0}(\boldsymbol{\Omega})$ & $\mathbf{Z I}(\mathbf{\Omega})$ & $\begin{array}{c}\text { Theor } \\
\mathbf{y}(\boldsymbol{\Omega})\end{array}$ & $\begin{array}{c}\text { Experimental } \\
\text { results( } \boldsymbol{(})\end{array}$ & data error \\
\hline 68 & 50 & $1: 36$ & $1: 28$ & 6 \\
\hline 75 & 50 & $1.5 \%$ & $1: 53$ & $2 \%$ \\
\hline 82 & 50 & 1.64 & 1.6 & $2 \%$ \\
\hline 100 & 50 & 2 & $2: 09$ & $4 \%$ \\
\hline 120 & 50 & 2.4 & $2: 53$ & $5 \%$ \\
\hline 150 & 50 & 3 & 3 & $0 \%$ \\
\hline 200 & 50 & 4 & $4: 33$ & $8 \%$ \\
\hline
\end{tabular}

Based on table 4.3 is obtained the percentage of errors with thevalue error at the lowest when using a resistor $150 \Omega$ is $0 \%$ and error the highest on the resistor $68 \Omega$ is $0.058823529 \%$ and the average number overall the data error resistor used is $4 \%$. According to the table can be graphed as in Figure 9 to facilitate the reading of the data.

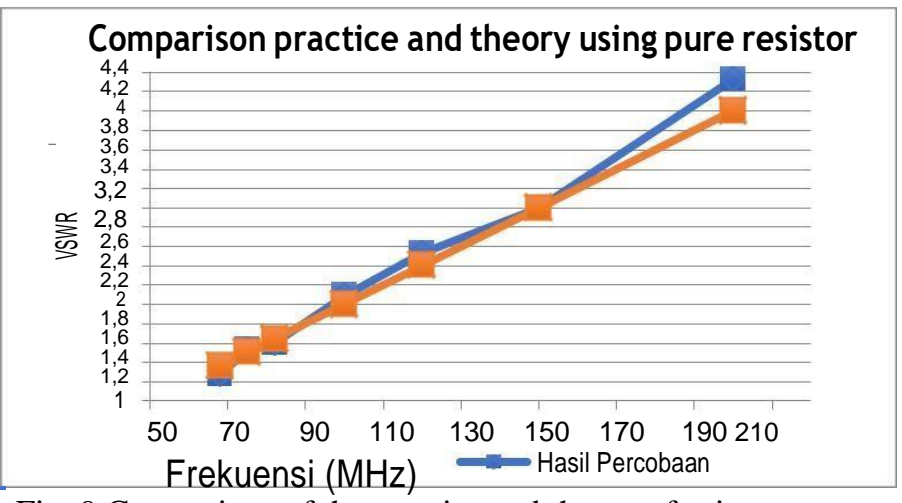

Fig. 9 Comparison of the practice and theory of using pure resistor

greater the value of the resistor is used then the measurement results of VSWR greater and much of the match, and getting closer to the value of $50 \mathrm{Ohm}$ resistor is used then the measurement of VSWR would be better to obtain the results obtained match the transmission line,

\section{MEASUREMENT OF SWR ANALYZER THE DUMMY LOAD}

Measurement is then performed using a dummy load with 50 Ohm load carried 25 times sweep in the frequency range of $6.9-7.4 \mathrm{MHz}$. 


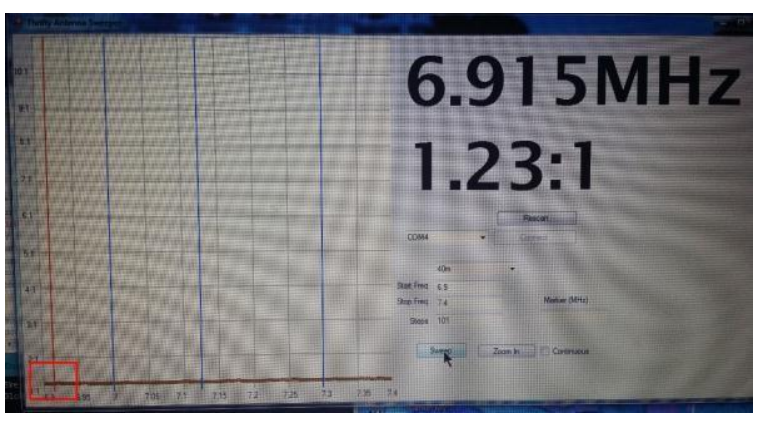

Fig. 10 The results of testing with a dummy load VSWR

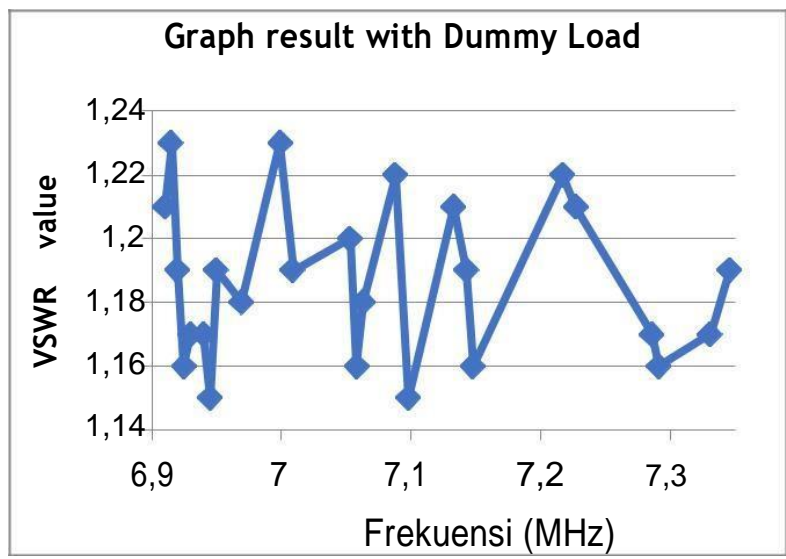

Fig. 11 Graph Results of testing with a dummy load VSWR

Based on figures 11 TestVSWR using Dummy Load performed at band 40mbandthe range frequency6.9 $\mathrm{MHz}$ - 7.4 MHz. 25 samples taken at testing data. Best VSWR value at a frequency of $6945 \mathrm{MHz}$ and 7098 with the acquisition value of VSWR at 1:15: 1, while the highest value reached 1:23 VSWR: 1 at a frequency of $6915 \mathrm{MHz}$ and $6999 \mathrm{MHz}$ and then obtained the average value of VSWR 1.1864. The resulting VSWR value at each frequency instability. However, in VSWR data generated in each of the frequency is still relatively in good condition with low VSWR value of 1:15 and 1:23 highest. Average Average difference between frequencies is 18167 $\mathrm{KHz}$.

\section{TEST RESULTS USING HF dipole antenna 7 MHZ}

VSWR value last test performed atantenna dipole 20:36 meteralong with 7:05 $\mathrm{MHz}$ operating frequency. Tests carried out on range the frequencyof 6.9 $\mathrm{MHz}$ - 7.4 MHz with a step frequency of 100 $\mathrm{KHz}$.

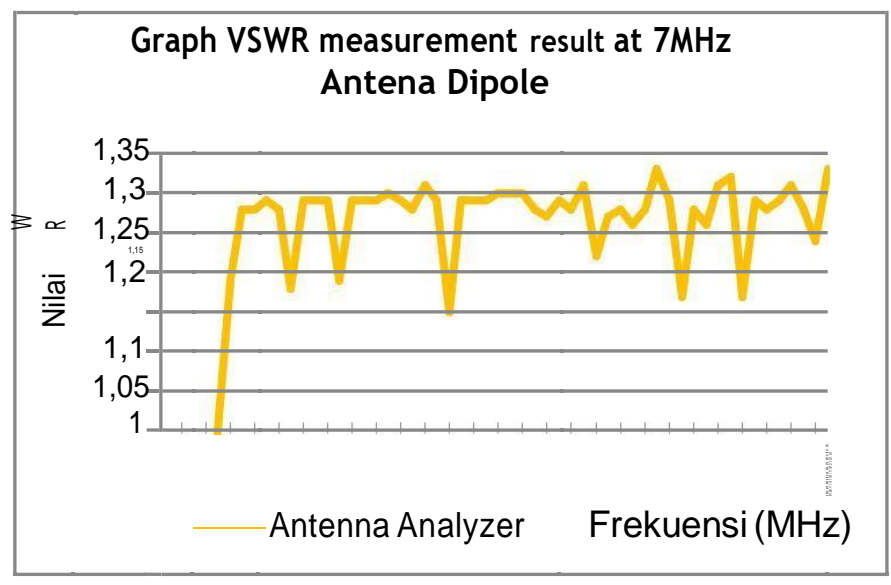

Fig. 12 Graph VSWR measurement results at $7 \mathrm{MHz}$ Dipole Antenna

testing conducted by Area obtained the best VSWR of 1: 1 at a frequency of $6.900 \mathrm{MHz}$ as in Figure 4.12, while the highest VSWR at a frequency of $7.4 \mathrm{MHz}$.

VSWR value is generated by using SWR Analyzer does not show stability. VSWR is constantly changing and it looks very significant changes between the frequency of 6.90 VSWR with the frequency of $6.91 \mathrm{MHz}$. VSWR value average is at 1:29 value.

\section{RESULTS COMPARISON OF MEASUREMENT VALUE VSWR USING SWR ANALYZER AND SWR BRIDGE}

After obtaining measurement data on the antenna, to prove that the SWR Analyzer is a measuring instrument VSWR that can be used in place SWR meter, then do a comparison between the measured data using the SWR Analyzer with measurement data SWR existing meter. The second methodAntenna Measurements were taken at Dipole the working frequency of $7 \mathrm{MHz}$. Tests carried out on range the frequencyof $6.9 \mathrm{MHz}$ to $7.4 \mathrm{MHz}$. The measurement results are presented in graphical form for easier reading. 


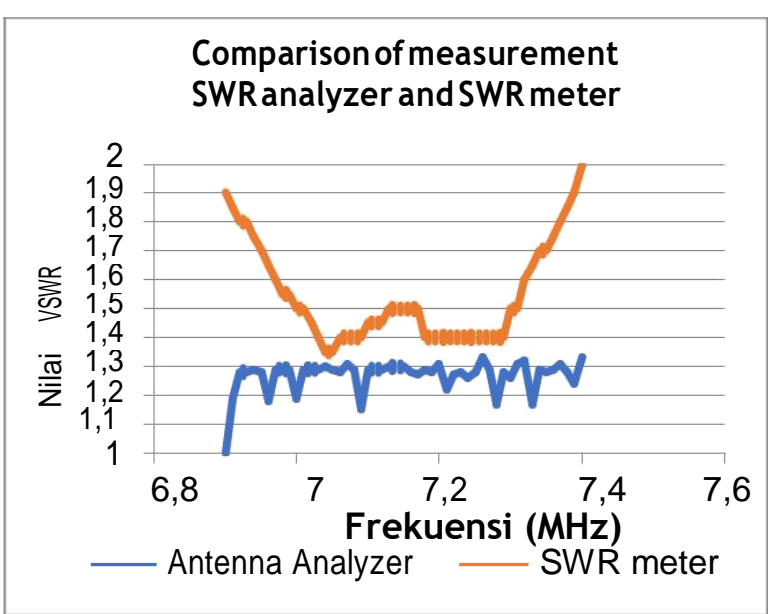

Fig. 13 Graph Comparison of measurement SWR Analyzer and SWR meter

graph in Figure 13 the measurement results using the SWR Analyzer can reach the point of match very well with the 1: 1 at a frequency of $6.9 \mathrm{MHz}$, while the measurement using the SWR meter measurements with VSWR best only on the value of 1.4: 1 . the graph is obtained from the comparison is formed like a mirror, where the frequency of $6.9 \mathrm{MHz}$ withmeasurement SWR Analyzer values obtained 1: 1 while the corresponding measurement data with the SWR meter shows the value of 1.9: 1. According to the theory, the value of VSWR would be even greater if further away the working frequency of the antenna and the smaller (match) when approaching the working frequency antennae. It can be said that the frequency of6.9 SWR Analyzer not provide accurate data because there is still a difference of 0.9 . Measurements using SWR Analyzer tend to be in the range of 1 to 1.3 with the acquisition of data that are less stable, while the measurement using the SWR meter is in conformity with the theory that the further measurement of the frequency of the working frequency of the antenna, VSWR values generated will be even greater. Measurements using the SWR meter hit a peak at a frequency of $6.9 \mathrm{MHz}$ and reached its lowest point at 7:04 $\mathrm{MHz}$ frequency until 7:05 MHz with VSWR 1:35 and then there was an increase to the frequency of 7.4 MHz with VSWR 2. Based on the data obtained by the accuracy of the measurement data using the SWR Analyzer amounted $83 \%$.

\section{CONCLUSION}

Based on research and testing that has been done, it can be concluded as follows:

1. It has been made a SWR Analyzer uses the AD9850 DDS can generate a sine wave with a frequency of $6.9 \mathrm{MHz}$ to $7.4 \mathrm{MHz}$.
2. The average accuracy of the output frequency by the AD9850 DDS amounted to $93 \%$ while the VSWR bridge circuit output by $98 \%$.

3. Calibration SWR Analyzer using pure resistor obtained an average error data at 0:37\%.

4. VSWR using Antenna analyzer with Dummy Load achieve the highest score of 1.23 while the lowest value on the value of 1:15.

5. The measurement results Dipole Antenna VSWR at $7 \mathrm{MHz}$ achieve perfect VSWR of 1: 1 at a frequency of $6.9 \mathrm{MHz}$, with the VSWR highest value reached $1: 33$ at $2 \mathrm{MHz}$ and the frequency is $7.4 \mathrm{MHz} 7: 26$.

6. The results of measurements using a VSWR value SWR Analyzer when compared with theSWR meter gained an average accuracy of data by $83 \%$.

The more the phase accumulator make the leap it will be slower generate a sine wave.

\section{References}

[1] Murphy, E. (2005). All About Direct Digital Synthesizer. Ask The ApplicationEngineering,33.

[2] ORARI. (1998). Basic Pengetahua Radio Communications. In O. Center, Dipole and Monopole Antenna (pp. 2-19). Jakarta: ORARI Center.

[3] Vankka, J. (2000). Direct Digital Synthesizer. In Theory, Design and Application. Helinsky Finland ..

[4] Hastuti, ND, and Iwan Iwut. (2008). DESIGN AND SIMULATION DDS (Direct Digital Synthesizer) ON. Final.

[5] Aprianah. (2013). Eprints. Retrieved February 2017 from Literature: http://webcache.googleusercontent.com/searc $\mathrm{h}$ ?q=cache:8ZH_opQRFqcJ:eprints.polsri.ac.i d/1157/3/BAB\%2520II.pdf+\&cd=5\&hl=id\&c $\mathrm{t}=\mathrm{clnk} \& \mathrm{gl}=\mathrm{id}$

[6] Permatasari, H., \& Prasetya, B. (2012). Planning and Implementation of Waveguide Slot Antenna with six slots in the $2.4 \mathrm{GHz}$ frequency antenna for $\mathrm{Wi}-\mathrm{Fi}$ applications. Final, 1 .

[7] Alaydrus, M. (2011). Antenna Principles and Applications. Yogyakarta: Graha Science.

[8] Sujendro,Henry,2013, "Antenna System Engineering", in http://belajar.ditpsmk.net/wpcontent/uploads/2014/09/perekayasaansistem-antena-3.pdf, accessed on 13 June 2017. 